\title{
A expansão e a avaliação dos cursos de História no Brasil
}

The expansion and the evaluation of History courses in Brazil

Fabiane Robl*

Paulo Eduardo Dias de Mello**

\section{Resumo}

$\mathrm{O}$ artigo aborda a relação entre a expansão e a avaliação dos cursos de História no Brasil, entre os anos de 2004 e 2012. A expansão dos cursos é analisada sob a ótica da categoria administrativa das Instituições de Educação Superior (público versus privado) e da organização acadêmica (Universidades, Centros Universitários, Faculdades e Institutos de Tecnologia). $\mathrm{Na}$ análise dos resultados das avaliações são considerados o conceito Enade e o Conceito Preliminar de Curso (CPC). Cabe destacar que as análises trarão o comparativo entre os cursos de Formação de Professores de História e os Cursos de Bacharelado em História.

Palavras-chave: avaliação; expansão; cursos de História.

\section{Abstract}

The article addresses the relationship between the expansion and the evaluation of the history courses in Brazil, between 2004 and 2012. The expansion of the courses will be analyzed from the perspective of administrative category of Institutions of Higher Education (public $\mathrm{x}$ private) and academic organization (Universities, University Centers, Colleges and Institutes of Technology). In analyzing the results of the evaluations will be considered the Enade concept and the Concept Preliminary Course (CPC). It should be noted that the analysis will bring the comparison between the courses of History Teacher Education and Bachelor courses in History. Keywords: evaluation; expansion; History courses.

Quais são os números da expansão do Ensino Superior no Brasil, especialmente dos cursos de História no Brasil? A que fatores essa expansão está intrinsecamente relacionada? Qual tem sido o papel do Poder Público e da iniciativa privada nesse processo? Quais são as relações entre a expansão e o processo de avaliação de cursos? O que esse processo de avaliação indica sobre a "qualidade" dos cursos de História oferecidos ao público? O que as três

\footnotetext{
* Doutora em Educação, Universidade de São Paulo (USP). fabiane.robl@gmail.com

** Doutor em Educação. Docente na Universidade Estadual de Ponta Grossa (UEPG). paulodemello04@gmail.com
} 
edições do Exame Nacional de Desempenho dos Estudantes (Enade) indicam sobre os Cursos de História? O que o Conceito Preliminar de Curso (CPC) revela sobre os cursos de História?

O escopo deste artigo é responder a algumas dessas indagações. Nossa análise principia discutindo a expansão dos cursos de História no Brasil nos últimos anos. O propósito é apontar alguns dos fatores que levaram a um processo de ampliação da oferta de cursos, com destaque para as relações com as Políticas de Formação de Professores, que consideramos uma importante chave explicativa do processo. Em seguida discutimos, como decorrência do processo de expansão, a instalação no país de um sistema de avaliação da Educação Superior. Essa discussão permite contextualizar a criação do Exame Nacional de Desempenho dos Estudantes (Enade) e introduzir uma análise sobre desempenho dos Cursos de História. Por fim, discutimos o Conceito Preliminar de Curso (CPC), um indicador de qualidade que é calculado no ano seguinte ao da realização do Enade de cada área, com base na avaliação de desempenho de estudantes, corpo docente, infraestrutura, recursos didático-pedagógicos e demais insumos.

\section{A expansão dos Cursos de História no Brasil e SUA

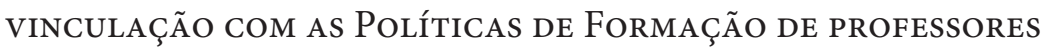

Na última década o Brasil passou por um importante processo de expansão da Educação Superior (ES) promovido por políticas educacionais pautadas por uma perspectiva de inclusão social e de articulação estratégica com a Educação básica. ${ }^{1}$ Quatro elementos se destacam nesse processo de expansão: a interiorização; a participação do setor privado; a ampliação da rede federal de ensino e a política nacional de formação de professores. Primeiro a expansão ocorre como parte de um movimento de "interiorização" da ES - tanto por parte do setor público quanto do privado - resultado de um processo de indução das políticas públicas, numa perspectiva de constituição de novos territórios de desenvolvimento econômico e social que visa superar a lógica estabelecida dos grandes centros de concentração do poder econômico, político, social e cultural. Nessa direção a expansão do ES é pensada como forma de deslocar o eixo educacional dos grandes centros e provocar o aparecimento e fortalecimento de novos centros visando o desenvolvimento regional. 
Por sua vez, o processo de expansão do setor privado decorre de outro movimento, identificado como expressão de um processo de "rearranjo" do capital, em que dezenas de pequenas instituições, sem condições de concorrer com as maiores, vêm sendo paulatinamente compradas por empresas educacionais de grande porte, formando enormes conglomerados. Ao mesmo tempo, demonstra também que o mercado percebeu que é mais fácil expandir por meio de IES com menores compromissos regulatórios, já que faculdades estão desobrigadas de um conjunto de requisitos elementares e constitucionais.

Além disso, a expansão do ES também pode ser considerada decorrência de um forte investimento da União na criação de novas Instituições de Ensino Superior (IES) em diferentes regiões do país, além da ampliação de cursos e vagas nas IES já existentes. Por fim, podemos relacionar o crescimento das licenciaturas à implementação da Política Nacional de Formação de Profissionais do Magistério da Educação, tais como o Plano Nacional de Formação de Professores da Educação Básica (Parfor), instituído pela Portaria Normativa $n^{\circ}$ 9/2009; o Programa de Iniciação à Docência (Pibid), instituído pelo Decreto 7.219/2010; e o Programa de Consolidação das Licenciaturas (Prodocência), instituído pela Portaria nº 119/2010.

Como veremos a seguir, os cursos de História participaram de forma significativa desse processo de expansão do ES no país. Na Tabela 1 podemos verificar alguns dados sobre a expansão dos cursos de História no Brasil (Bacharelado e Licenciatura) no período 2004-2012. Esses dados indicam um processo de reconfiguração da oferta de cursos de História, na última década, que pode ser resumido na grande expansão de cursos de licenciatura com maior participação do setor privado.

Os dados da Tabela 1 indicam um crescimento dos cursos de Licenciatura, entre 2004 e 2012, da ordem de 19,8\%, sendo 10,6\% no setor público e 32,9\% no setor privado. Nesse mesmo período o Bacharelado teve evolução inversa, com redução de $31,3 \%$ dos cursos, e no setor privado essa redução foi da ordem de $68 \%$. Observando os Gráficos 1 e 2 fica muito evidente a diferença na evolução dos cursos de Bacharelado e Licenciatura, por categoria administrativa. Os cursos de Bacharelado das IES privadas passaram por queda constante, especialmente a partir de 2008, mostrando a diminuição de interesse desse setor na oferta de tais cursos. Porém, o setor público mostrou avanços a partir de 2011 e se mantém estável. 
Tabela 1 - Número de Cursos de História

(Bacharelado e Licenciatura - 2004 a 2012

\begin{tabular}{c|c|c|c|c|c|c|c}
\hline \multirow{2}{*}{ Ano } & \multicolumn{3}{|c|}{ Bacharelado } & \multicolumn{3}{c|}{ Licenciatura } & \multirow{2}{*}{$\begin{array}{c}\text { Total } \\
\text { Geral }\end{array}$} \\
\cline { 2 - 7 } & Público & Privado & Total & Público & Privado & Total & \\
\hline 2004 & 52 & 47 & 99 & 253 & 176 & 429 & 528 \\
\hline 2005 & 51 & 40 & 91 & 208 & 138 & 346 & 437 \\
\hline 2006 & 53 & 41 & 94 & 252 & 219 & 471 & 565 \\
\hline 2007 & 56 & 46 & 102 & 214 & 232 & 446 & 548 \\
\hline 2008 & 58 & 45 & 103 & 221 & 247 & 468 & 571 \\
\hline 2009 & 86 & 43 & 129 & 150 & 217 & 367 & 496 \\
\hline 2010 & 42 & 20 & 62 & 232 & 238 & 470 & 532 \\
\hline 2011 & 34 & 20 & 66 & 231 & 230 & 463 & 529 \\
\hline 2012 & 53 & 18 & 71 & 273 & 228 & 501 & 572 \\
\hline 2013 & 53 & 15 & 68 & 280 & 234 & 514 & 582 \\
\hline
\end{tabular}

Fonte: MEC/Inep/Censo da Educação Superior. Elaboração dos autores.

Gráfico 1 - Distribuição dos Cursos de História (Bacharelado) por categoria administrativa

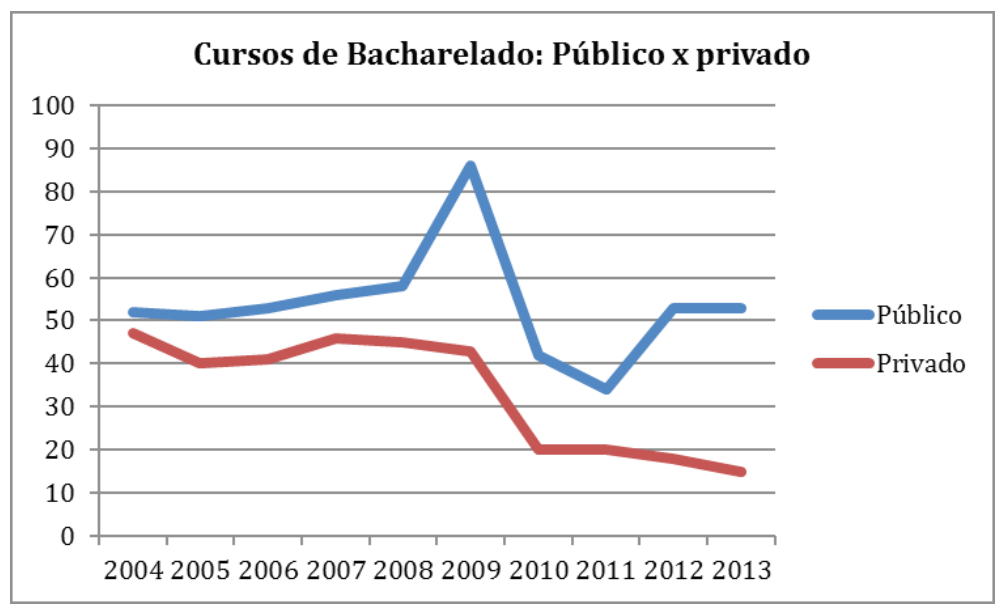


Gráfico 2 - Distribuição dos Cursos de História (Licenciatura) por categoria administrativa

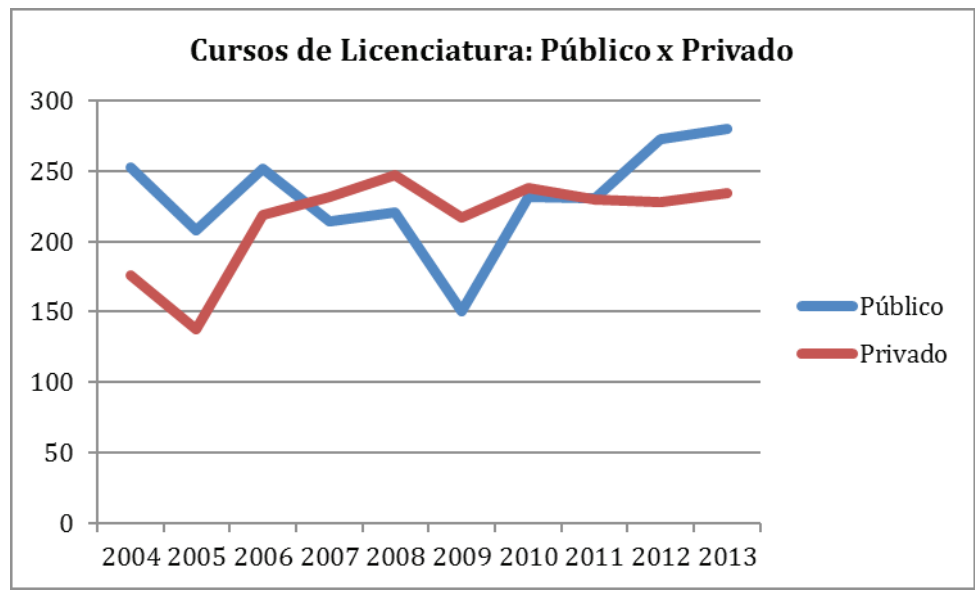

Como dissemos, podemos relacionar o incremento das licenciaturas à implementação da Política Nacional de Formação de Profissionais do Magistério da Educação e seus programas correlatos (Parfor, Pibid e Prodocência). Nesses programas podemos destacar que o curso de História respondeu por 5,07\% das vagas solicitadas no Parfor, em 2013, conforme dados da Capes expostos no Gráfico 3.

Gráfico 3 - Percentual de vagas solicitadas no Parfor em 2013

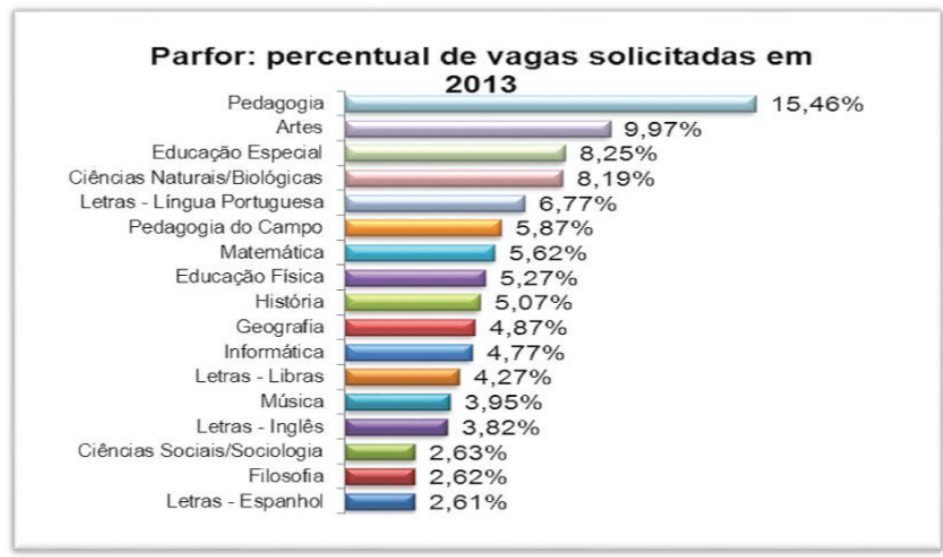

Fonte: Capes, Relatório de Gestão. 
Com relação à implantação de turmas, o curso de História respondeu por 3,82\%, ficando atrás, por exemplo, de Pedagogia (34,31\%), Matemática (8,86\%), Letras - Português (8,58\%) e Geografia (5,83\%).

Gráfico 4 - Percentual das turmas por curso no Parfor em 2013

\begin{tabular}{|c|c|}
\hline \multicolumn{2}{|c|}{$\begin{array}{c}\text { Parfor: Distribuição percentual das turmas por } \\
\text { curso, } 2009-2013\end{array}$} \\
\hline Pedagogia & 34,3 \\
\hline Matemática & $8,86 \%$ \\
\hline Letras - Portugues & $8,58 \%$ \\
\hline Geografia & $5,83 \%$ \\
\hline Biologia/Ciencias Biológicas & $4,57 \%$ \\
\hline Artes & $4,24 \%$ \\
\hline Letras - Ingles & $4,15 \%$ \\
\hline Licenciaturas Interdisciplinares/Integradas & $3,96 \%$ \\
\hline História & $3,82 \%$ \\
\hline Informática e computação & $3,68 \%$ \\
\hline Educaçăo Física & $3,36 \%$ \\
\hline Ciências Naturais & $3,03 \%$ \\
\hline Ciencias Sociais/Sociologia - & $2,47 \%$ \\
\hline Duímica & $2,38 \%$ \\
\hline Física & $1,96 \%$ \\
\hline Letras - Espanhol & $1,59 \%$ \\
\hline Filosofia & $1,12 \%$ \\
\hline Educaçāo Especial & $0,79 \%$ \\
\hline Religiăo & $0,61 \%$ \\
\hline Edcaçăo do Campo & $0,47 \%$ \\
\hline Licenciatura Indígena & J $0,23 \%$ \\
\hline
\end{tabular}

Fonte: Capes, Relatório de Gestão.

Para o Pibid, os dados revelam que o curso de História apresentou, ou foi contemplado com 174 projetos, distribuídos entre IES públicas e privadas. As públicas federais tiveram 80 projetos, as estaduais 60, e as municipais, 5. Dentre as privadas foram 29, sendo 27 em IES sem fins lucrativos e 2 em IES com fins lucrativos, totalizando 4.142 bolsas de iniciação à docência vinculadas aos cursos de História.

Assim, podemos inferir o aumento de cursos e matrículas nos cursos de licenciatura, dentre outros motivos, pela implementação de políticas de formação de professores em curso no Brasil, sobretudo a partir de 2009.

Podemos, no entanto, acrescentar outro fator que contribuiu para o processo de expansão dos cursos de História: a oferta de cursos na modalidade de Educação a Distância (EAD). 
Tabela 2 - Total de Cursos para Formação

de Professores de História - EAD (2012)

\begin{tabular}{c|c|c|c|c}
\hline \multirow{2}{*}{ Total } & \multicolumn{3}{|c|}{ Pública } & \multirow{2}{*}{ Privada } \\
\cline { 2 - 4 } & Federal & Estadual & Municipal & \\
\hline 30 & 4 & 7 & 1 & 18 \\
\hline
\end{tabular}

Fonte: MEC/Inep/ Daes. Elaboração dos autores.

Os dados da Tabela 2 indicam que em 2012 existia um total de 30 cursos para Formação de Professores de História, na modalidade EAD, dos quais 18 (60\%) eram do setor privado, e 12 (40\%) de instituições públicas. Os dados da Tabela 3 revelam que, do ponto de vista da organização acadêmica, as universidades são as maiores responsáveis por esse tipo de oferta, com 24 instituições (80\%) no total, oferecendo cursos EAD, sendo $50 \%$ delas privadas e $50 \%$ públicas, indicando um equilíbrio da oferta entre os setores quando consideramos a organização acadêmica. Apenas $20 \%$ dos cursos EAD são ofertados por outros tipos de instituições de ensino superior. Outro aspecto a ser sublinhado é que a participação da EAD na oferta global de cursos para Formação de Professores de História é ainda pequena. Somando-se os cursos presenciais e EAD (501, conforme a Tabela 4), esta modalidade representa uma fração de apenas $5,6 \%$ dos cursos.

Tabela 3 - Total de Universidades que ofertam Cursos para Formação de Professores de História - EAD. Brasil, 2012

\begin{tabular}{c|c|c|c|c}
\hline \multirow{2}{*}{ Total } & \multicolumn{3}{|c|}{ Pública } & \multirow{2}{*}{ Privada } \\
\cline { 2 - 4 } & Federal & Estadual & Municipal & \\
\hline 24 & 4 & 7 & 1 & 12 \\
\hline
\end{tabular}

Fonte: MEC/Inep/Daes. Elaboração dos autores.

O sistema de Avaliação da EducaÇão Superior no Brasil

O processo de expansão do ES no país foi acompanhado constantemente por uma preocupação com a questão da qualidade da educação ofertada. Em que pese a complexa discussão acerca do conceito de qualidade, destaca-se que, segundo a legislação vigente, as Instituições Federais de Educação Superior 


\begin{tabular}{|c|c|c|c|c|c|c|c|c|c|c|c|}
\hline & 尔 & & নे & मे & F & \& & \begin{tabular}{l}
$\infty$ \\
\hdashline \\
+
\end{tabular} & $\hat{n}$ & 웅 & ?̧ & 官 \\
\hline & ซ్ & 룽 & 1 & $n$ & 1 & 1 & 1 & 1 & - & - & -1 \\
\hline & $\stackrel{0}{0}$ & 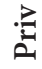 & 1 & 1 & 1 & 1 & 1 & 1 & 1 & 1 & 1 \\
\hline & $\underset{0}{ \pm} \underset{0}{U}$ & $\sum_{\Sigma}^{\Xi}$ & 1 & 1 & 1 & 1 & 1 & 1 & 1 & 1 & 1 \\
\hline 궁 & U : & $\begin{array}{c}\overrightarrow{5} \\
\text { w }\end{array}$ & 1 & 1 & 1 & 1 & 1 & 1 & 1 & 1 & 1 \\
\hline ' & & ర్ల & 1 & $m$ & 1 & 1 & 1 & 1 & - & $\neg$ & -1 \\
\hline تี兀 & & تే & $\sigma$ & $\infty$ & $\exists$ & 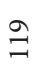 & $\stackrel{\bullet}{\sim}$ & $\Xi$ & 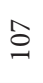 & తి & $\stackrel{ }{=}$ \\
\hline.$\tilde{乛}$ & $\frac{\mathscr{U}}{\partial}$ & 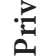 & $R$ & $\hat{\sigma}$ & $\infty$ & ลิ & $\stackrel{n}{\circ}$ & ฉ & $\infty$ & $\infty$ & $\infty$ \\
\hline$\stackrel{\pi}{5}$ & $\frac{\tilde{z}}{3}$ & $\sum_{\Sigma}^{\Xi}$ & $\stackrel{b}{-1}$ & $\stackrel{\sim}{\sim}$ & 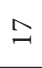 & $\stackrel{\infty}{-}$ & 드 & $\stackrel{m}{=}$ & $\stackrel{0}{0}$ & $\underset{0}{0}$ & $\stackrel{\infty}{\sim}$ \\
\hline$\Xi$ & & $\ddot{n}$ & 8 & ๖ & ¿̂ & J' & J & ชै & $\hat{\sigma}$ & J & $J^{\prime}$ \\
\hline$\stackrel{\overparen{Z}}{\underline{Z}}$ & & D & 1 & 1 & 1 & 1 & 1 & 1 & 1 & 1 & 1 \\
\hline 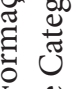 & $\stackrel{0}{\overparen{a}}$ & 풍 & లో & จे & Ғ & $\stackrel{\infty}{+}$ & $\bar{n}$ & $\stackrel{ }{\mathcal{F}}$ & $\vec{n}$ & in & भे \\
\hline 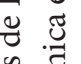 & क्ष் & 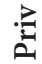 & ri & શે & Ғ & $\stackrel{\infty}{+}$ & $\bar{n}$ & F & $\bar{n}$ & in & $\stackrel{\infty}{+}$ \\
\hline 式 & $\underset{\Xi}{D}$ & $\sum_{\Sigma}^{\Xi}$ & 1 & 1 & 1 & 1 & 1 & - & 1 & 1 & -1 \\
\hline $\begin{array}{l}\varangle \\
8\end{array}$ & $\Xi$ & 武 & 1 & 1 & 1 & 1 & 1 & 1 & 1 & 1 & 1 \\
\hline.$\tilde{\mathbb{N}}$ & 0 & ర్ల & 1 & 1 & 1 & 1 & 1 & 1 & 1 & 1 & 1 \\
\hline$\stackrel{0}{0}$ & & 풍 & हे & ปิ & $\frac{m}{m}$ & ลิ & $\overline{\widehat{\lambda}}$ & $\underset{\sim}{\stackrel{J}{*}}$ & $\vec{m}$ & oे & F \\
\hline D & త్ర & 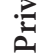 & $R$ & ㄱ & $\infty$ & $\infty$ & б & $\infty$ & ু & $\hat{a}$ & ஓ \\
\hline & $\stackrel{0}{0}$ & $\sum_{\Sigma}^{\Xi}$ & + & $m$ & + & $m$ & $m$ & in & $n$ & $\infty$ & $\stackrel{m}{-1}$ \\
\hline & 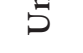 & 点 & $\underset{-\infty}{\not}$ & กี & $\stackrel{6}{I}$ & $\stackrel{\infty}{n}$ & $\stackrel{\infty}{ \pm}$ & สু & $\Xi$ & $\stackrel{\infty}{0}$ & ले \\
\hline & & D. & $\stackrel{9}{F}$ & $\approx$ & $\stackrel{\infty}{+\infty}$ & in & f & $\hat{m}$ & 2 & Һ & ¿ \\
\hline & & & ঠ্ণ & $\stackrel{\text { L }}{\stackrel{8}{\circ}}$ & ஓ̊ & ڤ્ণ & $\stackrel{\infty}{\stackrel{\leftrightarrow}{\circ}}$ & ठे & $\stackrel{\circ}{\circ}$ & 궁 & $\stackrel{\sim}{\stackrel{\sim}{\sim}}$ \\
\hline
\end{tabular}




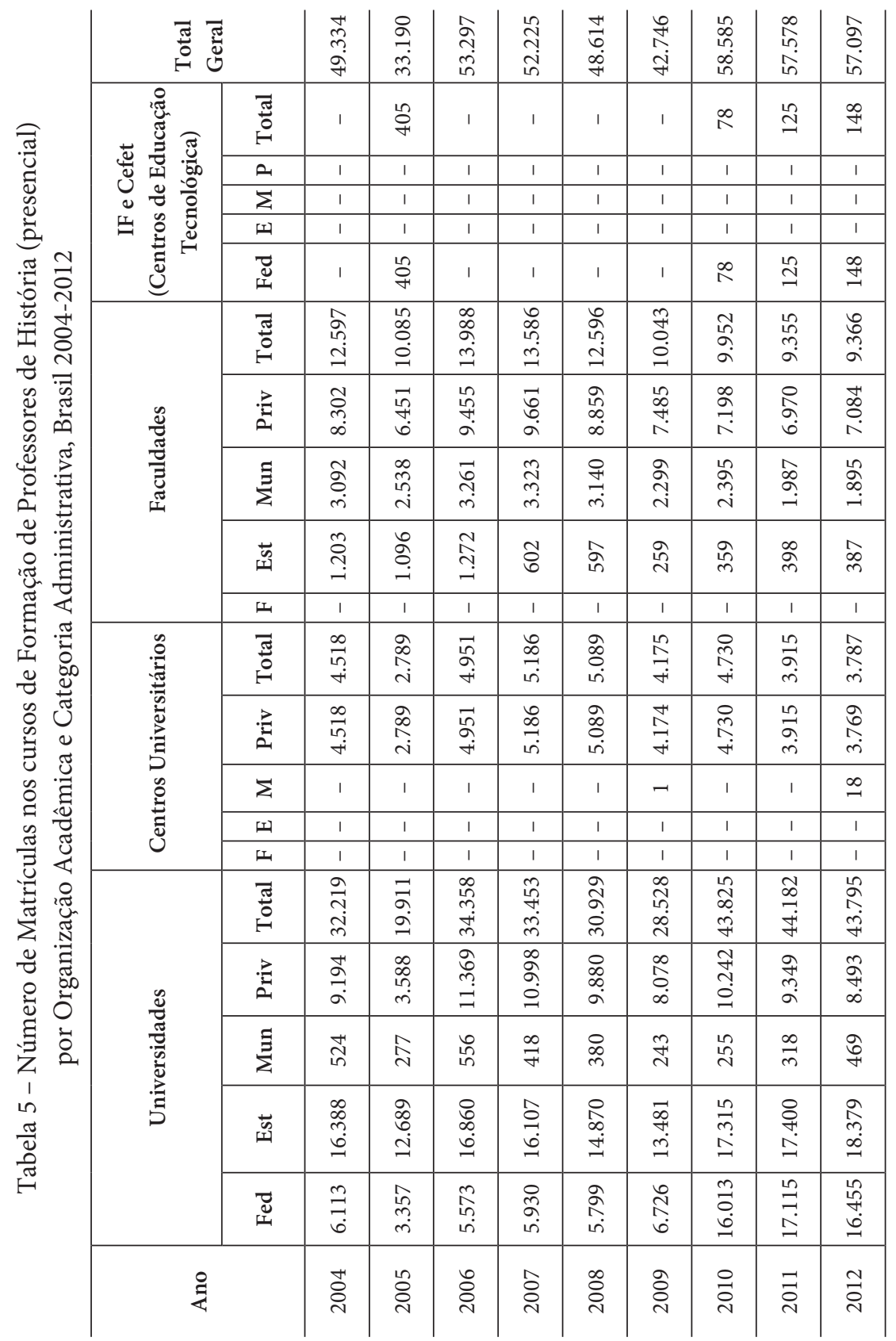


(Ifes) e as da iniciativa privada sem fins lucrativos somente podem implantar turmas em cursos de licenciatura que estejam devidamente credenciados no Sistema de Regulação do Ensino Superior (e-MEC) e que, quando avaliados, apresentarem Conceito de Curso (CC) igual ou superior a 3, e, na ausência deste, o CPC ${ }^{2}$ também deve ser igual ou superior a 3. No caso das IES estaduais e municipais, cujo curso não esteja cadastrado no e-MEC, poderá ser admitida a implantação de turmas mediante apresentação do documento de autorização do curso pelo órgão credenciado para tal fim.

Mas o que significa esse conceito de curso (CC igual ou superior a 3) e como ele é obtido? Para compreendê-lo precisamos, num primeiro momento, entender como o Sistema Nacional de Avaliação da Educação Superior (Sinaes) foi criado e quais as suas normativas.

A ideia de instaurar um processo de avaliação do Sistema de Educação Superior no Brasil começou a se espraiar e ter o apoio da comunidade acadêmica em meados da década de 1980, momento em que os movimentos docentes e as agências governamentais ligadas à educação superior, particularmente à pesquisa, discutiam a questão da necessidade da avaliação institucional, com motivações diferentes.

No interior das Universidades públicas, não sem contradições, desenvolveu-se a ideia de que a avaliação era necessária ao menos por dois motivos principais: como cumprimento do princípio de transparência e como mecanismo de fortalecimento da instituição pública ante as contínuas ameaças de privatização (Balzan; Dias Sobrinho, 2000, p.7).

Mas as primeiras tentativas nesse sentido partiram do Estado, com a criação do Programa de Avaliação da Reforma Universitária (Paru) e do Grupo de Estudos de Reforma da Educação Superior (Geres); ambos, porém, não renderam frutos, no sentido de dar continuidade ao processo. Após algumas experiências bem-sucedidas, conquanto isoladas, em 1993 teve início o Programa de Avaliação Institucional das Universidades Brasileiras (Paiub). Originado de um trabalho realizado por bases universitárias, mas adotado pelo governo federal, ele abriu espaços para um exercício emancipatório nas IES, diretamente vinculado à prática da avaliação.

Caracterizado por possuir "dotação financeira própria, livre adesão das universidades e princípios de avaliação coerentes com a posição emancipatória e participativa" (Leite, 2000), o Paiub permitiu que a avaliação formativa da ES no Brasil desse seu primeiro passo. Propunha a realização, nas instituições que a ele aderiam, de três momentos avaliativos: avaliação interna, avaliação externa e reavaliação. 
Analisando as lições e as experiências geradas com o Paiub, Dias Sobrinho afirma que:

As avaliações desenvolvidas no âmbito do Paiub e que seguem as orientações básicas deste Programa podem ser vistas a partir de distintos ângulos. Podem ser examinadas na perspectiva de sua função ou finalidade e, então, as classificamos predominantemente como formativas, no sentido de que são mais comumente internas e centradas no processo tendo em vista a melhoria da qualidade; são secundariamente também somativas, em muitos momentos, quando se dedicam, por exemplo, a quantificar ou determinar os diversos níveis de eficácia do objeto ... No caso do Paiub, as dimensões quantitativas e somativas servem para dar mais consistência e fundamentação à orientação educativa e formativa. Não têm, portanto, caráter controlador e hierarquizador. (Dias Sobrinho, 2003, p.82-83)

Entre 1993 e 1997, o Paiub procurou mostrar a importância, para a realidade brasileira, da associação entre avaliação, qualidade e transformação institucional. Tal fato o leva a ser tomado, ainda hoje, como referência, até mesmo por outros países. Considerando-se os números gerados entre 1994 e 1997, tem-se registrada a participação de 138 instituições no Paiub (Leite et al., 1999).

Tendo a dimensão formativa como princípio de uma política pública de avaliação da ES, em 2004 o governo federal instituiu o Sistema Nacional de Avaliação da Educação Superior (Sinaes) pela Lei 10.861 de 14 de abril de 2004. A lógica do Sinaes vai além da política de controle e verificação, característica das ações para a educação superior da década anterior, em especial, pelo Exame Nacional de Cursos (ENC). Ao se contrapor à avaliação realizada verticalmente (do MEC para as IES e cursos), com fins classificatórios, o Sinaes evidenciou a importância de uma avaliação compreensiva e pedagógica que, partindo da IES, a ela retorna, em um processo que passa pela ação mediadora do poder público.

O Sinaes tem por objetivo assegurar o processo nacional de avaliação das instituições de educação superior, dos cursos de graduação e do desempenho acadêmico de seus estudantes. Compreende o Exame Nacional de Desempenho dos Estudantes (Enade); a avaliação institucional (autoavaliação e avaliação externa, AIE); e a avaliação dos cursos de graduação (ACG).

A avaliação da educação superior proposta pelo Sinaes caracteriza-se por contextualizar diferentes procedimentos de avaliação, e por estar alinhada à percepção desta enquanto instrumento de política educacional voltado para a 
defesa da qualidade, da participação e da ética na educação superior. É comprometida com a transparência de seus processos e fundamentada nas diretrizes gerais já estabelecidas na legislação.

Na Lei 10.861/2004 que criou o Sinaes, os processos avaliativos são apresentados como "referencial básico" para a regulação estatal, cabendo aos órgãos competentes utilizarem-se dos resultados obtidos na avaliação externa, avaliação de discentes e avaliação de cursos para regular e definir políticas da competência do poder público. Ela foi regulamentada pelo Decreto Federal no 5.773, de 9 de maio de 2006, que estabelece as diferentes competências e funções dos órgãos governamentais envolvidos com "atos administrativos autorizativos do funcionamento de instituições de educação superior e de cursos de graduação e sequenciais", entendidos como regulação (Art. $1, \S 1^{\circ}$ ). Quanto à avaliação, 0 Decreto estabelece seu objetivo e relação com a regulação: “A avaliação realizada pelo Sistema Nacional de Avaliação da Educação Superior (Sinaes) constituirá referencial básico para os processos de regulação e supervisão da educação superior, a fim de promover a melhoria de sua qualidade" (Art. $1, \S 3^{\circ}$ ). Com isso, no Brasil os processos de avaliação são utilizados para fins de regulação.

\section{O Exame Nacional de Desempenho dos Estudantes (Enade): uma análise dos Cursos de História nas três edições do Exame}

O Exame Nacional de Desempenho dos Estudantes (Enade) é aplicado aos ingressantes e concluintes, de forma a verificar o IDD, Indicador de Diferença no Desempenho entre o Ingressante e o Concluinte. Com isso geram-se dois conceitos, o Conceito Enade e o Conceito IDD, ambos na escala aritmética de cinco níveis. A cada ano o MEC edita uma Portaria escolhendo os cursos a serem avaliados, geralmente adotando o critério de agrupamento pelas grandes áreas do conhecimento. Para efeitos do Exame o MEC considera aluno ingressante aquele que tiver cursado até $22 \%$ da carga horária do curso. E alunos concluintes são aqueles que cursaram pelo menos $80 \%$ dessa carga horária.

Atualmente, apenas os concluintes fazem o exame, embora os ingressantes devam ser inscritos, para posterior dispensa. A partir de 2011 a nota do aluno no Enem passou a compor o IDD, ao invés da nota do ingressante.

O Enade é de aplicação trienal nas áreas estabelecidas por portaria. No caso dos Cursos de História, a primeira edição ocorreu em 2005, a segunda em 2008 e a terceira em 2011, de forma que temos um ciclo completo para a área. Ou seja, estão disponíveis para análise os conceitos obtidos em três edições do 
exame. Em 2014, a área também foi selecionada, contudo os resultados ainda não estão disponíveis.

A Tabela 6 traz o montante de cursos que participaram das três edições do exame. Os dados revelam que em 2005, os estudantes de 408 cursos de história participaram do exame, o que representou 93,3\% do total de cursos existentes na área. Em 2008 esse percentual passou para 91,2\%, ou seja, 430 participaram de um total de 471 . Na edição seguinte, 2011, o percentual de participação reduziu-se para $72,8 \%$. Essa redução justifica-se pelo fato de que o Enade, em 2011, passou a ser aplicado apenas aos concluintes, de modo que a avaliação não contempla o boom de novos cursos, os quais serão avaliados somente quando tiverem formandos.

Tabela 6 - Número de cursos de História que participaram do Enade em 2005, 2008 e 2011 - por organização acadêmica

\begin{tabular}{c|c|c|c|c|c}
\hline Ano & Universidades & $\begin{array}{c}\text { Centros } \\
\text { Universitários }\end{array}$ & Faculdades & Total & $\begin{array}{c}\text { Total geral de } \\
\text { cursos da área }\end{array}$ \\
\hline 2005 & - & - & - & 408 & 437 \\
\hline 2008 & 255 & 54 & 121 & 430 & 471 \\
\hline 2011 & 251 & 45 & 89 & 385 & 529 \\
\hline
\end{tabular}

Fonte: MEC/Inep/Daes - Enade, 2005, 2008 e 2011. Elaboração dos autores.

De acordo com os dados dos Relatórios Enade 2005, 2008 e 2011, o curso de História teve, em 2005, 30.287 estudantes inscritos, sendo 16.150 ingressantes e 14.137 concluintes. Para a edição de 2008, foram convocados 24.115 estudantes, destes estiveram presentes 19.822, sendo 9.254 ingressantes e 10.568 concluintes. Em 2011 apenas concluintes realizaram a prova, sendo inscritos 16.687 estudantes, destes 12.616 estavam presentes. A abstinência, em 2005, foi de $18,4 \%$ para os ingressantes e 10,7\% para os concluintes. Em 2008, esse percentual passou para $21,3 \%$ entre os ingressantes e $13,9 \%$ entre os concluintes; e em 2011, as ausências representaram 24,4\%.

A prova do Enade é dividida em duas partes. A primeira, de Formação Geral, consiste em dez questões, duas das quais discursivas e oito objetivas. A segunda, de Componente Específico, é composta por trinta questões, entre discursivas e objetivas. 
Com relação ao desempenho vamos considerar apenas os dados referentes aos concluintes ${ }^{3}$ e às questões objetivas do componente de conhecimento específico.

Tabela 7 - Notas média, máxima e mínima do componente de conhecimento específico

\begin{tabular}{c|c|c|c}
\hline Ano & Média & Nota Máxima & Nota Mínima \\
\hline 2005 & 36,1 & 92,9 & 0,0 \\
\hline 2008 & 34,0 & 93,8 & 0,0 \\
\hline 2011 & 28,4 & 83,4 & 0,0 \\
\hline Licenciatura & 27,2 & 84,6 & 0,0 \\
\hline Bacharelado & 29,8 & 85,2 & 0,0 \\
\hline
\end{tabular}

Fonte: MEC/Inep/Daes - Enade/ 2005, 2008 e 2011. Elaboração dos autores.

Considerando a média obtida em cada edição do exame, percebemos que o desempenho veio diminuindo gradativamente: em 2005 a média foi 36,1; em 2008 caiu para 34,0 e, em 2011, atingiu 28,2. No comparativo licenciatura versus bacharelado, os dados de 2011 indicaram média um pouco superior para o bacharelado, 29,8, ao passo que a licenciatura não ultrapassou 27,2.

A questão passa a ser "Por que houve essa diminuição?". A prova ficou mais complexa ou o foi nível dos estudantes que se reduziu?

Embora o Inep divulgue nos relatórios específicos o desempenho no Enade detalhando as questões de formação geral e conteúdos específicos, as notas obtidas pelos estudantes, alguns itens do questionário socioeconômico e informações sobre o PPP de cada curso, todos esses insumos são convertidos em uma escala de 0 a 5, gerando o Conceito Enade.

Neste momento nosso interesse fica focado nas avaliações dos cursos de História, bem como na avaliação dos estudantes desses cursos. Trataremos então dos indicadores derivados da aplicação do Enade para os cursos de História, quais sejam: Conceito Enade e CPC.

\subsection{Conceito Enade 2005, 2008, 2011 dos Cursos de História}

Calcula-se o conceito do curso pela média ponderada da nota padronizada dos concluintes no componente específico, da nota padronizada dos ingressantes no componente específico e da nota padronizada em formação geral (concluintes e ingressantes), possuindo estas, respectivamente, os seguintes pesos: 
$60 \%, 15 \%$ e $25 \%$. Assim, a parte referente ao componente específico contribui com $75 \%$ da nota final do curso, enquanto a parte de formação geral contribui com 25\%. O conceito é apresentado em cinco categorias ( 1 a 5), onde 1 é o resultado mais baixo e 5 é o melhor resultado possível, na área.

Bittencourt et al. (2008) sintetizaram a conversão das notas em indicadores de 1 a 5 conforme detalhamento do Quadro 1.

$$
\text { Quadro } 1 \text { - Conceito Enade - conversão das notas em indicadores }
$$

1. Calcula-se a média e o desvio-padrăo de todos os alunos da instituiçăo que fizeram a prova, tanto ingressantes (I) como concluintes (C), tanto na formaçăo geral (FG) como no componente especifico (CE).

2. Calcula-se o afastamento padronizado (AP) para os seguintes grupos: $C E$ dos concluintes $\left(C^{C}\right)^{C}$ e dos ingressantes (CE') e FG dos ingressantes + concluintes $\left(\mathrm{FG}^{1+\mathrm{C}}\right)$. O AP é um escore que normalmente varia entre -3 e +3 . Ele indica quantos desvios-padrăo, acima ou abaixo da média, está o curso em relação aos demais concluintes da área.

3. Transforma-se o AP que geralmente varia de $-3 a+3$ para uma nota no intervalo de 0 a 5 . Esta nova escala é efetivamente usada para a atribuiçăo de conceitos. Os cursos que estäo abaixo de -3 e acima de +3 săo considerados atípicos e năo săo considerados para a mudança de escala. Aqueles que estăo abaixo de -3 recebem grau 0 e os que estăo acima recebem grau 5.

4. Calcula-se a média geral (MG) do curso levando-se em conta as três notas - $\mathrm{CE}^{\mathrm{C}}, \mathrm{CE}^{\prime}, \mathrm{FG}^{1+C}$ com as ponderaçöes de $60 \%, 15 \%$ e $25 \%$, respectivamente.

5. Define-se o conceito de acordo com a MG:

$\begin{array}{lccccc}\text { MG } & 0,0 \text { a } 0,9 & 1,0 \text { a } 1,9 & 2,0 \text { a } 2,9 & 3,0 \text { a } 3,9 & 4,0 \text { a } 5,0 \\ \text { Conceito } & 1 & 2 & 3 & 4 & 5\end{array}$

Fonte: Bittencourt et al., 2008.

Nas Tabela 8 e 9 apresentamos os conceitos Enade obtidos pelos Cursos de História separados por organização acadêmica (Universidade e Faculdades), e segundo sua categoria administrativa, ${ }^{4}$ abrangendo os anos de 2005, 2008 e 2011. Os dados disponíveis, no entanto, não favorecem comparações entre os cursos de Licenciatura e Bacharelado, pois essa distinção ficou estabelecida apenas na edição de 2011. Mas, ainda que isso possa limitar algumas análises, os dados fornecem elementos comparáveis interessantes, como por exemplo, a relação entre desempenho dos alunos segundo características institucionais (Universidades e Faculdades) e categoria administrativa (Setor Público Federal, Estadual e Municipal, e Setor Privado). 
Tabela 8 - Cursos ofertados por Universidades - distribuídos por Conceito Enade: 2005, 2008 e 2011

\begin{tabular}{|c|c|c|c|c|c|c|c|c|c|c|c|c|c|}
\hline & $\begin{array}{c}\text { Categoria } \\
\text { Administrativa }\end{array}$ & \multicolumn{3}{|c|}{ Federal } & \multicolumn{3}{|c|}{ Estadual } & \multicolumn{3}{|c|}{ Municipal } & \multicolumn{3}{|c|}{ Privada } \\
\hline \multirow{2}{*}{2005} & Conceito & $1 / 2$ & 3 & $4 / 5$ & $1 / 2$ & 3 & $4 / 5$ & $1 / 2$ & 3 & $4 / 5$ & $1 / 2$ & 3 & $4 / 5$ \\
\hline & História & 7 & 12 & 23 & 6 & 17 & 14 & 0 & 0 & 1 & 9 & 38 & 19 \\
\hline \multirow{2}{*}{2008} & Conceito & $1 / 2$ & 3 & $4 / 5$ & $1 / 2$ & 3 & $4 / 5$ & $1 / 2$ & 3 & $4 / 5$ & $1 / 2$ & 3 & $4 / 5$ \\
\hline & História & 8 & 18 & 23 & 45 & 32 & 18 & 0 & 1 & 1 & 8 & 35 & 27 \\
\hline \multirow{3}{*}{2011} & Conceito & $1 / 2$ & 3 & $4 / 5$ & $1 / 2$ & 3 & $4 / 5$ & $1 / 2$ & 3 & $4 / 5$ & $1 / 2$ & 3 & $4 / 5$ \\
\hline & Bacharelado & 6 & 5 & 9 & 2 & 2 & 0 & 0 & 0 & 0 & 1 & 2 & 6 \\
\hline & Licenciatura & 11 & 16 & 28 & 12 & 26 & 16 & 0 & 0 & 2 & 5 & 26 & 40 \\
\hline
\end{tabular}

Fonte: MEC/Inep/Daes. Elaboração dos autores.

Os dados da Tabela 8 indicam o desempenho dos cursos de História ofertados por Universidades. Em 2005 foram avaliados 146 cursos, em 2008 foram 216 , e em 2011, 215. Considerando a categoria administrativa dos cursos oferecidos por Universidades públicas, podemos verificar que, proporcionalmente, tem-se mantido certo equilíbrio nos conceitos obtidos pelas Universidades Federais, com um resultado que na média revela algo próximo a $20 \%$ dos cursos com conceito 1 ou 2, enquanto a maioria absoluta (80\%) obtém índice acima de 3 . A média geral dos cursos federais com conceito 4 ou 5 chega a $50 \%$ dos cursos. Os dados das Universidades Estaduais indicam um processo de crescimento da adesão ao Enade entre 2005 e 2008, da ordem de $82 \%$. Se retirarmos os dados referentes a 2008 (aparentemente inflacionados) podemos 


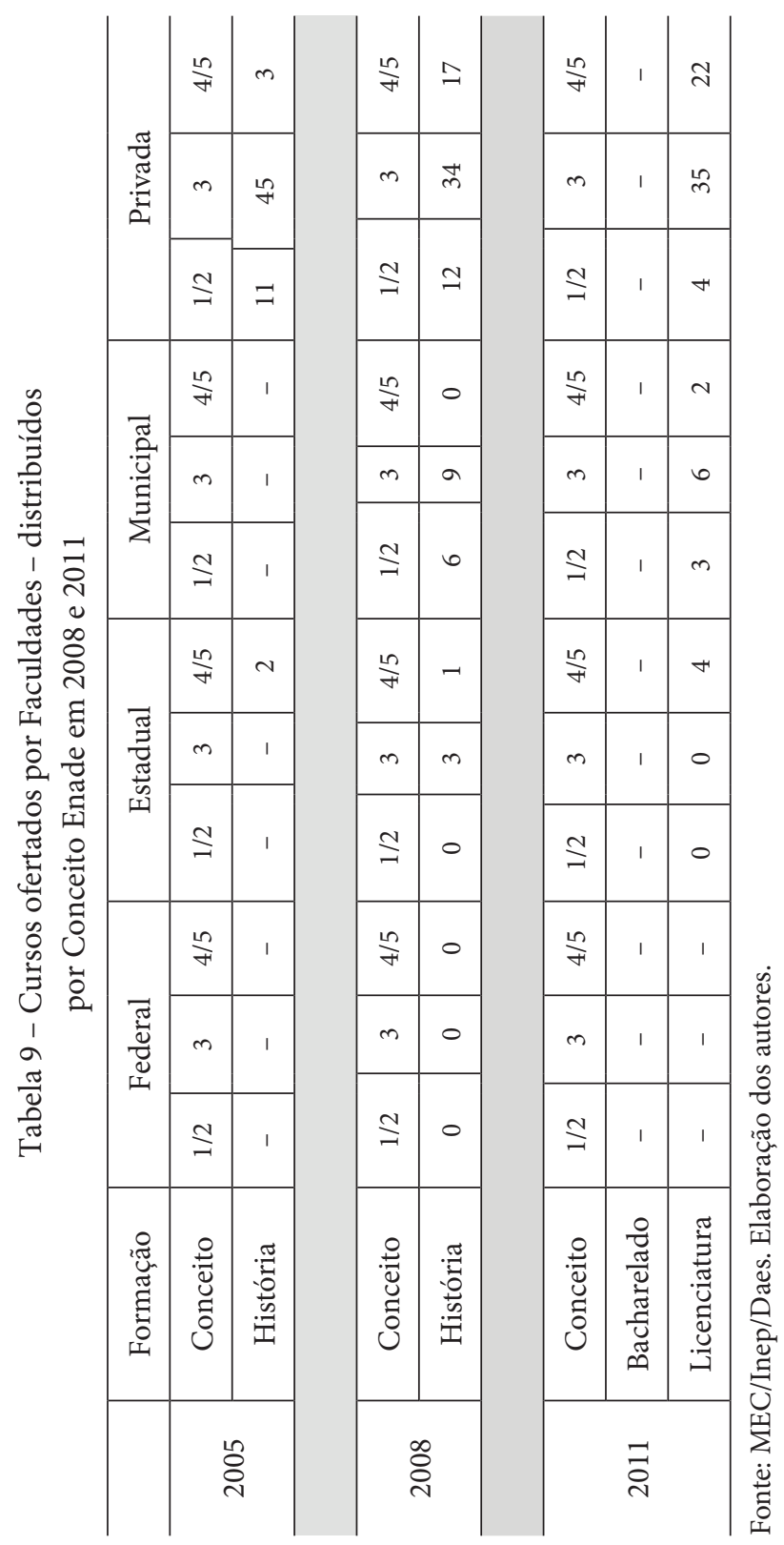


verificar, basicamente, a mesma proporção de instituições estaduais que obtiveram média 1 ou 2 no Enade, enquanto uma maioria se concentra nos conceitos 3 , 4 ou 5 .

Comparativamente, os dados indicam que um maior número de universidades federais tem obtido melhor desempenho, com índices 4 e 5, que as estaduais. Apenas uma análise mais qualitativa, no entanto, poderia determinar as razões dessas diferenças, mas podemos supor que os investimentos dos últimos anos realizados pelo governo federal na expansão dos cursos, melhorias na infraestrutura e investimentos em bolsas, possam ter contribuído para a manutenção da qualidade nas IES federais. Por sua vez, as estaduais parecem sofrer, na última década, em algumas realidades, um processo de desinvestimento do poder público.

Outro aspecto em que podemos estabelecer comparações a partir dos dados da Tabela 8 é sobre a relação entre IES públicas e privadas. Em 2005 foram avaliadas 80 IES Públicas e 66 privadas. Dessas, 38 IES públicas (47,5\%) obtiveram conceito 4 ou 5 , enquanto 19 IES privadas $(28,7 \%)$ obtiveram o mesmo conceito. Em 2008 foram avaliadas 146 IES públicas e 70 privadas. Dessas, 42 IES públicas $(28,7 \%)$ obtiveram o conceito 4 ou 5 , enquanto 27 IES privadas $(38,5 \%)$ obtiveram o mesmo conceito. Por fim, em 2011, tivemos 135 IES públicas avaliadas e 80 privadas. Desse total tivemos 55 IES públicas $(40,7 \%)$ com conceitos 4 ou 5, e 46 IES privadas (57,5\%) com o mesmo conceito. Uma leitura linear dos dados indica um equilíbrio na qualidade da oferta entre IES públicas e privadas, tendo estas últimas evoluído nos indicadores dos últimos exames. ${ }^{5}$

Em geral, é senso comum dizer que os cursos ofertados por Faculdades, em razão de suas características institucionais, são considerados de qualidade inferior às dos cursos ofertados por universidades, onde a pesquisa é apontada como elemento qualificador dos projetos pedagógicos dos cursos. Outro fator que contribui para essa percepção é o fato de a maioria das faculdades serem instituições do setor privado, marcado pelo estigma da precariedade das condições gerais de oferta dos cursos. Em 2011, por exemplo, tínhamos 15 faculdades públicas prestando o exame contra 61 privadas. Mas, o que revelam os dados de desempenho nas provas do Enade? Os dados da Tabela 9 permitem algumas indicações. 
Se considerarmos apenas as faculdades privadas que obtiveram conceito 4 ou 5, poderemos verificar uma boa evolução nos indicadores nas três edições do Enade, resultado, dentre outros fatores, exatamente das novas exigências impostas pela avaliação. Em 2005, do total de 59 faculdades privadas, apenas 3 (5\%) obtiveram conceito 4 ou 5 no Enade. Já em 2008 esse número elevou-se, passando a 17 (27\%) das faculdades privadas participantes. Em 2011 esse número teve novo incremento, chegando a 21 faculdades (36\%) com conceito 4 ou 5 no Enade. São vários os fatores que podem ser apontados como responsáveis por esse incremento no número de faculdades privadas com conceito positivo no Enade, dentre os quais destacamos o próprio processo de avaliação, além da vinculação com ações do MEC como o Programa Universidade para Todos, o Prouni. ${ }^{6}$

Até 2008, os conceitos decorrentes do exame apenas refletiam um diagnóstico do aprendizado do alunado para orientar readequações nos itinerários formativos no âmbito da própria IES, sem maiores efeitos externos. Contudo, o MEC instituiu dois indicadores vinculados ao Enade, no caso, o Conceito Preliminar de Cursos (CPC) e o Índice Geral de Cursos (IGC), também chamado pelo MEC de Indicador de Qualidade Institucional. Ambos têm implicações na Regulação e principalmente na Supervisão, pois resultados iguais ou maiores que 3 dispensam os cursos e as IES da avaliação in loco.

A criação dos indicadores de qualidade como o CPC e o IGC constituem uma das alterações da forma original como o Sinaes foi concebido. Não são avaliações, mas derivações dos processos de avaliação. A criação foi justificada pelo MEC por causa da impossibilidade logística de realizar todos os processos previstos no Sinaes, em seu primeiro ciclo avaliativo (2007-2009). Talvez por isso, e em decorrência da determinação da Lei do Sinaes, de avaliar todas as IES e cursos no ciclo de 3 anos, o MEC providenciou, a partir de 2008, mecanismos que permitiriam regularizar sua situação, pautando-se nos resultados do Enade. Para tanto, foram criados, com base nas Portarias Normativas $\mathrm{n}^{\circ}$ 40/2007, n 4/2008 e n ${ }^{\circ}$ 10/2009, dois índices, o Conceito Preliminar de Cursos (CPC) e o Índice Geral de Cursos (IGC). O primeiro teve por base o Conceito do Enade, o Conceito IDD e alguns insumos relativos ao Corpo Docente, sua titulação e regime de trabalho, além de aspectos da infraestrutura. Já o segundo considera a média do CPC de todos os cursos da IES, além dos dados de matrícula na graduação e pós-graduação, entre outros. 
A contribuição do Enade, no entanto, é de mensuração complicada. Há críticas no sentido de que o Enade pode assumir as mesmas características do extinto Exame Nacional de Cursos (ENC) quando assume a tarefa de nutrir dois indicadores preliminares, atribuídos ao curso e à IES. Mas, ao mesmo tempo é inegável que seus resultados, tanto o Conceito Enade, o IDD, quanto as notas de Formação Geral e Conteúdo Específico, são fortes elementos para redirecionar a ação pedagógica da IES.

A literatura que tem foco no Enade tende a compará-lo com o ENC, sobretudo destacando que o atual exame possui as mesmas limitações e que seus resultados, embora prometessem avaliar o desempenho do aluno, terminam por constituir-se como referencial do desempenho da IES ou, ainda, que o Enade aponta a baixa qualidade da Educação Superior Brasileira. Não vamos enumerar aqui os autores que vão por esse caminho, mas as revistas de avaliação estão repletas de artigos dessa natureza.

Ora, os resultados do Enade são uma proxy de eficácia da política de ensino da IES e também da qualidade do projeto pedagógico. Não é adequado olhar para os resultados finais e entendê-los como reflexo automático da boa ou má qualidade de um curso ou do desempenho da IES. O Enade tem como referencial os conteúdos previstos nas Diretrizes Curriculares Nacionais (DCNs). Ele avalia o domínio de conteúdos programáticos previstos nas DCNs nos três eixos de formação (geral, específica e profissionalizante).

Portanto, o exame avalia, sobretudo, a didática do projeto do curso e ao mesmo tempo a capacidade que o aluno tem de apreender os conteúdos formativos. Como entender que curso bom é aquele com nota 5 no Enade, se as normas educacionais admitem que o aproveitamento se dê na casa dos $75 \%$. Perceba-se que a regulamentação do aproveitamento no âmbito do projeto do curso admite que o aluno deixe de apreender um conjunto notável dos conteúdos previstos nas DCNs. Entendido desta forma, torna-se equivocada a análise que diz que os cursos avaliados com nota 3 no Enade demonstram baixa qualidade. Pelo contrário, a nota 3 sinaliza um grau de aproveitamento e percepção dos conteúdos dentro da lógica assumida pela DCNs, conforme explicitado no Parecer CNE/CES n ${ }^{\circ}$ 67/2003, que deliberara sobre o "Referencial para as Diretrizes Curriculares Nacionais - DCN dos Cursos de Graduação”. 
Contudo, o uso dos resultados do Enade pelas políticas públicas fica evidenciado nas ações e programas do MEC, uma vez que são considerados, por exemplo, para fins de ampliação das bolsas do Prouni e financiamento via Fies, em que as resoluções e portarias normativas indicam que serão considerados, entre outros critérios: "o conceito obtido pelo curso no Exame Nacional de Desempenho dos Estudantes (Enade), na hipótese de inexistência do CC e do CPC".

De qualquer forma, o resultado do Enade está presente, visto que o CPC é, de acordo com o Inep,

uma média de diferentes medidas da qualidade de um curso. As medidas utilizadas são: o Conceito Enade (que mede o desempenho dos concluintes), o desempenho dos ingressantes no Enade, o Conceito IDD e as variáveis de insumo. $\mathrm{O}$ dado variáveis de insumo - que considera corpo docente, infraestrutura e programa pedagógico - é formado com informações do Censo da Educação Superior e de respostas ao questionário socioeconômico do Enade.

Podemos citar também como exemplo os programas vinculados à Política Nacional de Formação de Profissionais do Magistério da Educação: i) Plano Nacional de Formação de Professores da Educação Básica (Parfor), instituído pela Portaria Normativa $n^{\circ}$ 9/2009; ii) Programa de Iniciação à Docência (Pibid), instituído pelo Decreto 7.219/2010; e iii) Programa de Consolidação das Licenciaturas (Prodocência), instituído pela Portaria n 119/2010.

Para a participação nestes programas as IES públicas e privadas (sem fins lucrativos) obrigatoriamente devem apresentar IGC igual ou superior a 3. No caso do Parfor, as turmas somente poderão ser implantadas em cursos avaliados com CPC ou CC também igual ou superior a 3. Desta forma, como o CPC utiliza o conceito Enade na sua base de cálculo, podemos dizer que $o$ Enade tem vinculação direta com a oferta de cursos neste programa de formação de professores.

Assim, os resultados do Enade são utilizados sobretudo pelo Estado como mecanismo regulador, sem necessariamente um fim de diagnóstico. O estabelecimento de rankings também é uma consequência dos resultados, não pela nota na prova, mas sim pelo índice gerado.

Para Brito (2008) é importante destacar que o Enade, que é um exame em larga escala, não avalia a ênfase do curso, mas sim os itens que constam das 
diretrizes curriculares nacionais, comuns a todos os cursos e a partir dos quais os projetos são construídos. Compete ao avaliador de curso, na visita in loco, verificar a compatibilidade entre a ênfase, a realidade social e o perfil do profissional graduado pela IES. Assim, não podemos inferir o resultado do Enade à qualidade ou não de determinado curso. Ou seja, não se pode dizer que um curso 3 seja menos qualificado que um curso 4 ou 5, o que se pode dizer é apenas que um curso 4 agrega mais que um curso 3, por exemplo. Para aferir a qualidade seria preciso primeiro defini-la e estabelecer critérios para sua aferição.

\section{Análise do CPC para os cursos de História}

O Conceito Preliminar de Curso (CPC) é construído com base nas avaliações do Enade. ${ }^{7}$ De acordo com o Inep, o CPC é um indicador de qualidade que é calculado no ano seguinte ao da realização do Enade de cada área, com base na avaliação de desempenho de estudantes, corpo docente, infraestrutura, recursos didático-pedagógicos e demais insumos, conforme orientação técnica aprovada pela Conaes.

O CPC tem impacto sobre a renovação do reconhecimento dos cursos existentes. Conforme as portarias vigentes, podem ter dispensa de avaliação para fins de renovação de reconhecimento cursos com CPC acima de 3. Embora a norma diga que cursos entre 3 e 4 podem ter dispensa, e que obtendo 5 sua dispensa é automática, na prática todos terminam tendo suas renovações automáticas.

Desta forma, os dados da Tabela 10 indicam que, dos 162 cursos de História ofertados por Universidades e que apresentaram CPC válido em 2008, apenas 13 deveriam passar por avaliação in loco, pois obtiveram conceito inferior a 3. Devemos lembrar, também, que as universidades estaduais e municipais respondem ao sistema estadual de avaliação, não sendo, portanto, obrigadas a se submeterem às regras do Sinaes. Assim, os 13 cursos citados são 7 de universidades federais e 6 de universidades privadas. Se considerarmos o universo de IES públicas federais que deveriam passar por avaliação in loco, teríamos $15 \%$ delas, para $10 \%$ das IES privadas. Somando-se as estaduais, no entanto, o número de IES públicas elevar-se-ia a $30 \%$. 
Tabela 10 - Cursos ofertados por Universidades - distribuídos por CPC em 2008

\begin{tabular}{c|c|c|c|c|c|c|c|c|c|c|c|c}
\hline $\begin{array}{c}\text { Categoria } \\
\text { Administrativa }\end{array}$ & \multicolumn{3}{|c|}{ Federal } & \multicolumn{3}{c|}{ Estadual } & \multicolumn{3}{c}{ Municipal } & \multicolumn{3}{c}{ Privada } \\
\hline Conceito & $1 / 2$ & 3 & $4 / 5$ & $1 / 2$ & 3 & $4 / 5$ & $1 / 2$ & 3 & $4 / 5$ & $1 / 2$ & 3 & $4 / 5$ \\
\hline História & 7 & 19 & 20 & 22 & 28 & 4 & 1 & 2 & 0 & 6 & 28 & 25 \\
\hline
\end{tabular}

Fonte: MEC/Inep/Daes. Elaboração dos autores.

Com relação as Faculdades, 56 delas apresentaram conceito válido em 2008 e, destas, 19 obtiveram resultado inferior a 3, portanto 33\% deveriam passar por avaliação in loco, indicando um quadro de precariedade das condições de ensino dessas instituições independentemente da situação administrativa.

Tabela 11 - Cursos ofertados por Faculdades - distribuídos por CPC em 2008

\begin{tabular}{c|c|c|c|c|c|c|c|c|c|c|c|c}
\hline $\begin{array}{c}\text { Categoria } \\
\text { Administrativa }\end{array}$ & \multicolumn{3}{|c|}{ Federal } & \multicolumn{3}{c|}{ Estadual } & \multicolumn{3}{c|}{ Municipal } & \multicolumn{3}{c}{ Privada } \\
\hline Conceito & $1 / 2$ & 3 & $4 / 5$ & $1 / 2$ & 3 & $4 / 5$ & $1 / 2$ & 3 & $4 / 5$ & $1 / 2$ & 3 & $4 / 5$ \\
\hline História & 0 & 0 & 0 & 0 & 3 & 1 & 6 & 4 & 0 & 13 & 25 & 4 \\
\hline
\end{tabular}

Fonte: MEC/Inep/Daes. Elaboração dos autores.

Por fim, se considerarmos apenas o caráter público ou privado das IES, independente de sua categoria administrativa e acadêmica, em média, temos 16,5\% dos cursos das IES públicas e 19\% das IES privadas que deveriam passar um processo de avaliação in loco.

Nas Tabelas 12 e 13 apresentamos os CPC para os cursos de História Licenciatura e Bacharelado, separadamente. Ocorre que em 2011 passou a existir a divisão nos dados entre a Licenciatura e o Bacharelado, ao passo que até 2008, a nomenclatura utilizada era apenas "História". Em 2011 foram totalizados 155 cursos de Licenciatura em Universidades e 49 em Faculdades, chegando ao total geral de 253 cursos. 
Tabela 12 - Cursos ofertados por Universidades - distribuídos por CPC em 2011

\begin{tabular}{c|c|c|c|c|c|c|c|c|c|c|c|c}
\hline $\begin{array}{c}\text { Categoria } \\
\text { Administrativa }\end{array}$ & \multicolumn{3}{|c|}{ Federal } & \multicolumn{3}{c|}{ Estadual } & \multicolumn{3}{c}{ Municipal } & \multicolumn{3}{c}{ Privada } \\
\hline Conceito & $1 / 2$ & 3 & $4 / 5$ & $1 / 2$ & 3 & $4 / 5$ & $1 / 2$ & 3 & $4 / 5$ & $1 / 2$ & 3 & $4 / 5$ \\
\hline Bacharelado & 2 & 9 & 5 & 0 & 3 & 1 & 0 & 3 & 0 & 0 & 1 & 8 \\
\hline Licenciatura & 5 & 21 & 27 & 6 & 30 & 12 & 0 & 0 & 2 & 0 & 15 & 37 \\
\hline
\end{tabular}

Fonte: MEC/Inep/Daes. Elaboração dos autores

Tabela 13 - Cursos ofertados por Faculdades distribuídos por CPC em 2011

\begin{tabular}{c|c|c|c|c|c|c|c|c|c|c|c|c}
\hline $\begin{array}{c}\text { Categoria } \\
\text { Administrativa }\end{array}$ & \multicolumn{3}{|c|}{ Federal } & \multicolumn{3}{c|}{ Estadual } & \multicolumn{3}{c}{ Municipal } & \multicolumn{3}{c}{ Privada } \\
\hline Conceito & $1 / 2$ & 3 & $4 / 5$ & $1 / 2$ & 3 & $4 / 5$ & $1 / 2$ & 3 & $4 / 5$ & $1 / 2$ & 3 & $4 / 5$ \\
\hline Bacharelado & - & - & - & - & - & - & - & - & - & - & - & - \\
\hline Licenciatura & 0 & 0 & 0 & 5 & 3 & 3 & 0 & 0 & 0 & 1 & 31 & 16 \\
\hline
\end{tabular}

Fonte: MEC/Inep/Daes. Elaboração dos autores.

Do total de 155 cursos de Licenciatura em História, apenas 62\% apresentaram conceito Enade válido em 2011. Os dados de 2011 indicam que as instituições privadas concentravam o maior número de cursos de Licenciatura com desempenho 4/5 (37 IES, 24\% do total de IES), seguido das IES Federais (27 IES, 17,4\%); e IES Estaduais (12 IES, 7,7\%).

Os dados do Bacharelado em História indicam praticamente o mesmo quadro, com $90 \%$ dos cursos de IES privadas obtendo conceito $4 / 5$, contra $33 \%$ das IES Federais. É bom frisar que as Faculdades não oferecem cursos de bacharelado, ou não apresentam conceito. $\mathrm{Na}$ verdade, apareceu apenas uma instituição: a Escola Superior de Ensino Anísio Teixeira (Cesat), com sede em Serra, no Espírito Santo, cuja faixa de conceito do CPC foi SC (Sem conceito), ou seja, não foi efetuado o cálculo por não haver número suficiente de concluintes para a realização do Enade. 
Para Barreyro e Rothen (2014) os índices não constituem um processo de melhoria de qualidade, afinal, dispensando-se visitas para os cursos que apresentam a nota mínima aceitável (3) e também para os bons e excelentes (4 e 5), sinaliza-se conformidade e acomodação. Mas, sobretudo, é preciso frisar que os conceitos obtidos precisam ser relativizados. Afinal, seria preciso identificar, em primeiro lugar, as variáveis que interferem na avaliação, tais como processos de preparação dos alunos para melhoria do desempenho no Enade, além de outros como a "maquiagem" da infraestrutura dos cursos.

\section{CONSIDERAÇÕES FINAIS}

Buscamos neste artigo responder a algumas indagações provocadas pela expansão dos cursos de História no Brasil nos últimos anos. Para tanto apontamos alguns dos fatores que explicam o processo de ampliação da oferta de cursos na última década, com destaque para as relações com as Políticas de Formação de Professores, que consideramos uma importante chave explicativa desse processo. Efetivamente, a expansão dos cursos de História está relacionada a sua função social direcionada à Educação Básica.

Em decorrência do processo de expansão verificamos como ocorreu no país a instalação de um sistema de avaliação da Educação Superior. Foi nesse contexto que se criou o Exame Nacional de Desempenho dos Estudantes (Enade). Os dados apresentados possibilitaram algumas comparações segundo diferentes critérios, mas sua contribuição para qualificação dos cursos é de complicada mensuração. Verificamos que o exame avalia, sobretudo, a didática do projeto do curso e, ao mesmo tempo, a capacidade que o aluno tem de apreender os conteúdos formativos, mas não avalia a ênfase do curso. Além disso, o exame tem adquirido importância significativa para credenciar ou não a oferta de cursos em programas federais de formação de professores. Assim, os resultados do Enade têm sido utilizados pelo Estado como mecanismo regulador, sem necessariamente exercer uma finalidade de diagnóstico.

Por fim, discutimos o Conceito Preliminar de Curso (CPC), um indicador de qualidade que é calculado no ano seguinte ao da realização do Enade de cada área, com base na avaliação de desempenho de estudantes, corpo docente, infraestrutura, recursos didático-pedagógicos e demais insumos. Esse instrumento tem impacto importante sobre a renovação do reconhecimento dos cursos 
existentes, indicando ou não a necessidade da avaliação in loco. Efetivamente, no entanto, eles não constituem um processo de melhoria de qualidade, indicando até mesmo possíveis distorções produzidas pelo instrumento.

Em suma, é preciso de alguma forma aprofundar os debates sobre como avaliar a expansão de cursos de História no país. Desenhar novos critérios e instrumentos, fomentar discussões acerca dos indicadores e dos dados produzidos. Afinal, não basta avaliar, é preciso discutir e produzir ações com base nos dados obtidos. Um deles talvez seja, exatamente, discutir a própria avaliação.

\section{REFERÊNCIAS}

BALZAN, Newton C.; DIAS SOBRINHO, José (Org.) Avaliação Institucional - teorias e experiências. São Paulo: Cortez, 2000.

BARREYRO, Gladys Beatriz; ROTHEN, José Carlos. Percurso da avaliação da educação superior nos Governos Lula. Educação e Pesquisa, Brasil, v.40, n.1, p.61-76, mar. 2014. ISSN 1678-4634. Disponível em: www.revistas.usp.br/ep/article/ view/81861/85145; Acesso em: 30 mar. 2015. DOI: http://dx.doi.org/10.1590/ S1517-97022014000100005.

BELLONI, Isaura; MAGALHÃES, Heitor de; SOUSA, Luzia C. de. Metodologia de Avaliação em Políticas Públicas - Uma experiência em Educação profissional. 4.ed. São Paulo: Cortez, 2007. (Questões da Nossa Época, 75).

BITTENCOURT, Helio R.; VIALI, Lorí; CASARTELLI, Alam O.; RODRIGUES, Alziro C. M. Uma análise da relação entre os conceitos Enade e IDD. Estudos em Avaliação Educacional, v.19, n.40, maio/ago. 2008.

BRASIL. Lei n 10.861 de 14 abr. 2004. Institui o Sistema Nacional de Avaliação da Educação Superior - SINAES e dá outras providências. 2004. Disponível em: www.planalto.gov.br/legislação.

BRASIL. Ministério da Educação. Sistema Nacional de Avaliação da Educação Superior: da Concepção à Regulamentação. Brasília: Inep, 2004.

. Comissão Nacional de Avaliação da Educação Superior. Diretrizes para a avaliação das Instituições de Educação Superior. Brasília, 2004.

Lei no 10.861, de 14 abr. 2004. Institui o Sistema Nacional de Avaliação da Educação Superior - SINAES. Brasília, 2004.

Decreto Federal no. 5773 de 9 maio 2006. Dispõe sobre o exercício das funções de regulação, supervisão e avaliação de instituições de educação superior. DOU, Brasília, 10 maio 2006. 
BRITO, Márcia Regina F. de. O SINAES e o ENADE: da concepção à implantação. Revista Avaliação, Campinas, v.13, n.3, nov. 2008.

DIAS SOBRINHO, José. Avaliação da Educação Superior. São Paulo: Cortez, 2003. . Avaliação Institucional, instrumento da qualidade educativa - a experiência da UNICAMP. In: DIAS SOBRINHO, José; BALZAN, Newton C. (Org.) Avaliação Institucional: teoria e experiências. São Paulo: Cortez, 1995.

HOUSE, Ernest R. Evaluación Ética e Poder. 3.ed. Madrid: Morata, 2000.

INEP. Censo da Educação Superior. Disponível em: www.inep.gov.br/superior/censosuperior/.

LEITE, Denise. Avaliação e democracia: possibilidades contra-hegemônicas ao redesenho capitalista das universidades. s.d. Disponível em: http://bibliotecavirtual. clacso.org.ar/ar/libros/mollis/leite.pdf.

Modernidade e Pós-Modernidade na Educação superior. Educação Agrícola Superior, Brasília, v.18, p.13-20, 2000.

LEITE, Denise; CUNHA, Maria Isabel; LUCARELLI, Elisa; VEIGA, I.; FERNANDES, C. M. B.; BRAGA, Ana Maria; GENRO, M. E.; FERLA, A.; CAMPANI, A.; CAMPOS, M.; ALVES, E.; NOLASCO, L. Inovação na Universidade: a pesquisa em parceria. Interface. Comunicação, Saúde e Educação, Botucatu, SP, v.3, n.4, p.4152, 1999.

RISTOFF, Dilvo I. Avaliação Institucional: pensando princípios. In: BALZAN, Newton C.; DIAS SOBRINHO, José. Avaliação Institucional: teoria e experiências. São Paulo: Cortez, 1995.

\section{NOTAS}

${ }^{1}$ Estas políticas foram implementadas no país a partir dos governos do Partido dos Trabalhadores (PT) nas gestões de Luís Inácio Lula da Silva (2003-2010) e Dilma Rousseff (20112014).

${ }^{2}$ Segundo nota do Instituto Nacional de Estudos e Pesquisas Educacionais Anísio Teixeira (Inep), o Conceito Preliminar de Curso (CPC) é um indicador de qualidade que avalia os cursos superiores. Ele é calculado no ano seguinte ao da realização do Exame Nacional de Desempenho dos Estudantes (Enade) de cada área, com base na avaliação de desempenho de estudantes, corpo docente, infraestrutura, recursos didático-pedagógicos e demais insumos, conforme orientação técnica aprovada pela Comissão Nacional de Avaliação da Educação Superior (Conaes).

${ }^{3}$ Para fins de comparação entre as edições do exame, optamos por trabalhar apenas com as notas dos concluintes, uma vez que em 2011 somente estes estudantes realizaram a prova. 
${ }^{4}$ Segundo o artigo 19 da LDB 9394/96, as instituições de ensino dos diferentes níveis classificam-se nas seguintes categorias administrativas: I - públicas, assim entendidas as criadas ou incorporadas, mantidas e administradas pelo Poder Público; II - privadas, assim entendidas as mantidas e administradas por pessoas físicas ou jurídicas de direito privado. $\mathrm{O}$ artigo 20, por sua vez, estipula que as instituições privadas de ensino se enquadram em 4 categorias: I - particulares em sentido estrito, assim entendidas as que são instituídas e mantidas por uma ou mais pessoas físicas ou jurídicas de direito privado que não apresentem as características dos incisos abaixo; II - comunitárias, assim entendidas as que são instituídas por grupos de pessoas físicas ou por uma ou mais pessoas jurídicas, inclusive cooperativas de professores e alunos que incluam na sua entidade mantenedora representantes da comunidade; II - comunitárias, assim entendidas as que são instituídas por grupos de pessoas físicas ou por uma ou mais pessoas jurídicas, inclusive cooperativas educacionais, sem fins lucrativos, que incluam na sua entidade mantenedora representantes da comunidade; (Redação dada pela Lei no 12.020 , de 2009); III - confessionais, assim entendidas as que são instituídas por grupos de pessoas físicas ou por uma ou mais pessoas jurídicas que atendem a orientação confessional e ideologia específicas e ao disposto no inciso anterior; e IV - filantrópicas, na forma da lei. Disponível em: www.planalto.gov.br/CCIVIL_03/leis/L9394.htm; Acesso em: 13 jun. 2015.

${ }^{5}$ Vale lembrar as distinções já apontadas na nota anterior sobre a diversidade de IES privadas. Os dados oferecidos, no entanto, não nos permitem avaliar o desempenho entre as diferentes categorias de IES privadas, especialmente entre as com fins lucrativos e as sem fins lucrativos.

${ }^{6}$ O Programa Universidade para Todos (Prouni) tem como finalidade a concessão de bolsas de estudo integrais e parciais em cursos de graduação e sequenciais de formação específica, em instituições de ensino superior privadas. Criado pelo Governo Federal em 2004 e institucionalizado pela Lei no 11.096, em 13 jan. 2005, oferece, em contrapartida, isenção de tributos àquelas instituições que aderem ao Programa. Conferir em: http://prouniportal.mec.gov.br/o-programa; Acesso em: 13 jun. 2015.

${ }^{7}$ Os cursos de História passaram pelo exame em 2005, 2008 e 2011, mas como o índice foi constituído apenas em 2007, não temos os valores referentes a 2005. Assim, a análise do CPC contemplará apenas os anos de 2008 e de 2011.

Artigo recebido em 16 de julho de 2015. Aprovado em 16 de julho de 2015. 